\title{
Effect of gas-dynamic spraying parameters on the characteristics of coatings for steel shaft
}

\author{
Alexey Ponomarev*, Sergey Plakhov, Andrew Aksenov, and Andrey Popov \\ Kaluga Branch of Moscow State Technical University after N.E. Bauman, 248000 Kaluga, Russia
}

\begin{abstract}
In this article, the effect of the powder composition and energy parameters of the gas-dynamic deposition mode on the hardness of coatings of low-carbon steel samples was studied. Technological recommendations for preliminary preparation of the base metal of shafts before gas-dynamic spraying of thin layers in order to increase the strength of their adhesion are proposed.
\end{abstract}

The shafts of various machines and mechanisms in heavy engineering are mainly made of structural steels. The surfaces of the steel shafts are often restored by various metalbuilding methods when detecting defects after machining or during repair. For example, in the production of turbine plants, low-carbon steel shafts of the Steel 20 type are coated with layers up to $0.5 \mathrm{~mm}$ thick with a hardness ranging from 80 to 120 Vickers units [1]. This hardness corresponds to the hardness of non-ferrous metals such as aluminum, zinc, and copper. Therefore, one of the possible methods of building up metal for turbine steel shafts is gas-dynamic spraying of powders based on aluminum, zinc and copper.

Gas dynamic spraying is a method of spraying in which powder particles in a nozzle are accelerated by a supersonic stream of warm air. The air is heated by the DIMET thermoelectric element to temperatures from 50 to 150 degrees Celsius [2].

The research of the coating hardness after gas-dynamic spraying was carried out on three control samples - plates (Fig. 1).

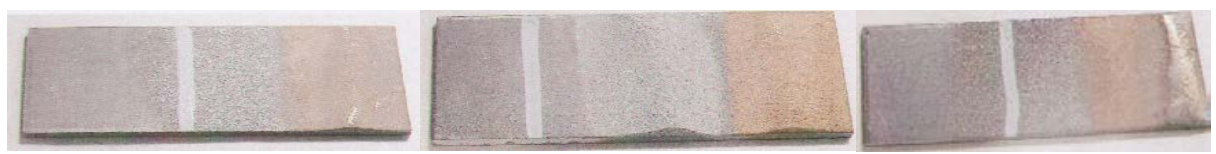

Fig. 1. Control samples after spraying.

Spraying was carried out using a DIMET-405 plant in the modes shown in Table 1 . The distance from the nozzle to the sample surface was $10 \ldots 11 \mathrm{~mm}$. The hardness of the coating on the control samples was measured with a "Duramin-5" micro-hardness meter at a load of $100 \mathrm{~g}$. Micro-hardness according to the Vickers scale took values from 63.1 to 137.9 units (Table 2).

According to the results of the research, the hardness of the samples after gas-dynamic deposition of copper and copper-zinc powder with the addition of corundum meets the

\footnotetext{
* Corresponding author: apon2005@yandex.ru
} 
requirements for the surface hardness of shafts made of low-carbon steels of the Steel 20 type. In this case, spraying should be performed in the modes indicated in table. 1.

Table 1. Parameters of the gas-dynamic spraying for samples.

\begin{tabular}{|c|c|c|c|}
\hline \multirow{2}{*}{$\begin{array}{c}\text { Sample } \\
\text { number }\end{array}$} & \multicolumn{2}{|c|}{ Process modes } & \multirow{2}{*}{ Coating components } \\
\cline { 2 - 3 } & $\begin{array}{c}\text { Air stream heating: } \\
\text { degree Celsius }\end{array}$ & $\begin{array}{c}\text { Powder feed: } \\
\text { kg per second }\end{array}$ & \\
\hline $1 \mathrm{a}$ & 80 & 0.0016 & $\mathrm{Al}+\mathrm{Zn}+$ corundum \\
\hline $1 \mathrm{~b}$ & 80 & 0.0022 & $\mathrm{Cu}+$ corundum \\
\hline 2 & 80 & 0.0027 & $\mathrm{Cu}+\mathrm{Zn}+$ corundum \\
\hline 3 & 80 & 0.0031 & $\mathrm{Cu}+\mathrm{Zn}+$ corundum \\
\hline
\end{tabular}

Table 2. Results of sample research.

\begin{tabular}{|c|c|c|c|}
\hline $\begin{array}{c}\text { Sample } \\
\text { number }\end{array}$ & Powder brand & Powder composition & Vickers Microhardness \\
\hline $1 \mathrm{a}$ & A-80-13 & Aluminum, zinc & $63.1 \ldots 69.2$ \\
\hline $1 \mathrm{~b}$ & C-01-01 & Copper & $99.5 \ldots 109.2$ \\
\hline 2 & C-01-11 & Copper, zinc & $100.1 \ldots 135.2$ \\
\hline 3 & C-01-11 & Copper, zinc & $107.9 \ldots 137.9$ \\
\hline
\end{tabular}

Unlike plates, during gas-dynamic spraying of cylindrical surfaces, a helical line is formed with partial overlapping of nearby rollers. At the same time, in order to avoid defects in roughness, the edges of the rollers should be smooth. To determine the influence of the spraying parameters on the width of a single roller with even edges, a research was carried out by the method of experiment planning [3]. When drawing up the experiment plan, two factors were taken as variables: the powder consumption $\left(X_{1}\right)$ and the temperature of the air mixture during spraying $\left(X_{2}\right)$.the response parameter was the width of the roller ( $B)$, which largely determines the quality of the coating. A constant factor was the nozzle departure during spraying, equal to $10 \mathrm{~mm}$ with possible deviations of $1 \mathrm{~mm}$.

As the plate spraying experiments showed, smooth edges of the rollers are obtained at a heated air temperature in the range of $80 \ldots 150$ degrees Celsius, and a powder flow rate corresponding to the range from 0.002 to $0.003 \mathrm{~kg} / \mathrm{s}$. Based on this, the upper, main (zero), and lower levels of the experiment planning factors were selected (table 3 ).

Table 3. Levels of experiment planning factors.

\begin{tabular}{|c|c|c|c|c|c|}
\hline \multirow{2}{*}{ Factor } & Name & \multicolumn{3}{|c|}{ Levels } & \multirow{2}{*}{ Interval } \\
\cline { 3 - 5 } & Temperature, C & $\begin{array}{c}\text { lower } \\
(-1)\end{array}$ & $\begin{array}{c}\text { main } \\
(0)\end{array}$ & $\begin{array}{c}\text { upper } \\
(+1)\end{array}$ & 35 \\
\hline$X_{1}$ & 80 & 115 & 150 & 35 \\
\hline$X_{2}$ & $\begin{array}{c}\text { Powder consumption, } \\
\mathrm{kg} / \mathrm{s}\end{array}$ & 0.002 & 0.0025 & 0.003 & 0.0005 \\
\hline
\end{tabular}

As an experiment plan, we used a matrix of a complete two-factor experiment without zero levels of factors. The scheme of planning the main experiments is based on the principle of repeating combinations of levels of the first factor for the lower and upper values of the second. Table 4 shows the data of the experiment and the necessary 
procedures for its statistical analysis. According to the obtained values of the response function, the coefficients of the linear regression equation of the form were found: $y=b_{0}+b_{1} x_{1}+b_{2} x_{2}+b_{12} x_{1} x_{2}$. To find the unknown coefficients of the model and check their significance according to the results of n-parallel experiments, the arithmetic mean values of the response function $\bar{y}_{j}$ and its variance $s_{y}^{2}$ were calculated (Table 4).

Table 4. Planning matrix and the results of the experiment.

\begin{tabular}{|c|c|c|c|c|c|c|c|c|c|c|}
\hline \multirow{3}{*}{$\begin{array}{l}\text { Exp. } \\
\text { number }\end{array}$} & \multicolumn{5}{|c|}{ Factor level } & \multicolumn{3}{|c|}{$\begin{array}{l}\text { Parallel exp. } \\
\quad(r=3)\end{array}$} & \multirow{3}{*}{$\bar{y}_{j}$} & \multirow{3}{*}{$s_{y}^{2}$} \\
\hline & \multicolumn{2}{|c|}{ Natural units } & \multicolumn{3}{|c|}{ Encoded values } & \multirow{2}{*}{$y_{j 1}$} & \multirow{2}{*}{$y_{j 2}$} & \multirow{2}{*}{$y_{j 3}$} & & \\
\hline & $X_{1}$ & $X_{2}$ & $X_{0}$ & $X_{1}$ & $X_{2}$ & & & & & \\
\hline 1 & 150 & 0.003 & + & + & + & 8.0 & 7.8 & 8.2 & 8.0 & 0.04 \\
\hline 2 & 80 & 0.003 & + & - & + & 7.3 & 7.1 & 6.6 & 7.0 & 0.13 \\
\hline 3 & 150 & 0.002 & + & + & - & 6.6 & 6.5 & 6.4 & 6.5 & 0.01 \\
\hline 4 & 80 & 0.002 & + & - & - & 4.8 & 5.0 & 5.2 & 5.0 & 0.04 \\
\hline
\end{tabular}

The uniformity of dispersions was tested using the Fisher test according to the following condition: dispersions are uniform if $F_{\text {calc }} \leq F_{\text {table }}$ :

$$
F_{\text {calc }}=\frac{s_{\max }^{2}}{s_{\min }^{2}}=\frac{0.13}{0.01}=13
$$

The variances are uniform, since for a hypothesis with a $95 \%$ confidence probability and two degrees of freedom $F_{\text {calc }}=13 \leq F_{\text {table }}=19$.

The variance of reproducibility of the experiment for 4 experiments $(\mathrm{N}=4)$ is equal to:

$$
s_{y}^{2}=\frac{1}{N} \cdot \sum_{j=1}^{N} s_{j}^{2}=\frac{0.22}{4}=0.055
$$

The unknown coefficients of the regression equation are calculated as follows using formulas using the least squares method:

$$
\begin{aligned}
& b_{0}=\frac{1}{N} \sum_{j=1}^{N} \bar{y}_{j}=\frac{8+7+6.5+5}{4}=6.625 ; \\
& b_{1}=\frac{1}{N} \sum_{j=1}^{N} X_{i j} \bar{y}_{j}=\frac{8-7+6.5-5}{4}=0.625 ; \\
& b_{2}=\frac{1}{N} \sum_{j=1}^{N} X_{i j} \bar{y}_{j}=\frac{8+7-6.5-5}{4}=0.875 ; \\
& b_{12}=\frac{1}{N} \sum_{j=1}^{N} X_{i j} X_{l j} \bar{y}_{j}=\frac{8-7-6.5+5}{4}=-0.125,
\end{aligned}
$$

$I, l$ - are the factor numbers; $X_{i j}, X_{l j}$ - are the encoded values of factors; $I$ and $l$ on $j$-th experience.

To check the significance of the coefficients of the regression equation, we calculate the variance of the coefficients and their confidence intervals. The dispersion $i$-th coefficient is 
equal to: $s^{2}\left\{b_{i}\right\}=\frac{1}{n \cdot N} \cdot s_{y}^{2}=\frac{1}{3 \cdot 4} \cdot 0.055=0.00458$. Confidence interval $\Delta b_{i}$ was determined using the Student's t-criterion using the formula:

$$
\Delta b_{i}= \pm t_{T} s\left\{b_{i}\right\}= \pm 2.78 \cdot 0.0677= \pm 0.188 .
$$

The coefficient $b_{12}$ was considered statistically insignificant, since it did not exceed its confidence interval in absolute value. As a result of the calculations of the coefficients, the regression equation took the following form:

$$
y=6.625+0.625 \cdot x_{1}+0.875 \cdot x_{2}
$$

After switching from the encoded values of the factors to the natural values and after conversion, the regression equation has the following form:

$$
B=0.1965+0.0178 \cdot T+17.5 \cdot Q
$$

$B$ - width of a single roller; $T$ - temperature; $Q$ - the consumption of powder.

The resulting response surface (Fig. 2) allows us to conclude that high-quality gasdynamic deposition of steel shafts will occur at a single roller width of $6.5 \mathrm{~mm}$ with permissible deviations of $1.5 \mathrm{~mm}$ in both directions.

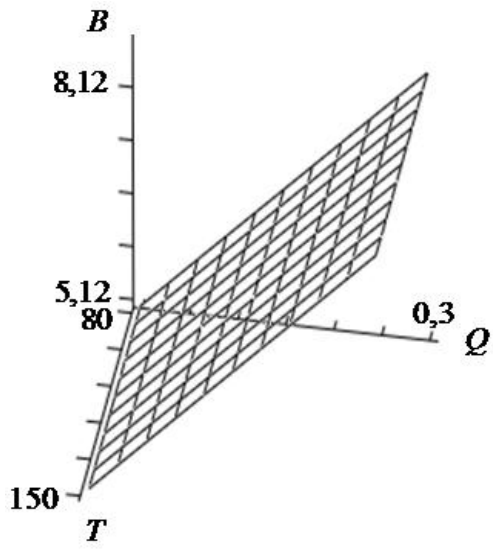

Fig. 2. The surface response.

To study the adhesion strength of the coating after gas-dynamic spraying of copper powder on steel shafts during subsequent turning, samples (false shafts) were prepared in the form of stepped shafts made of steel 20. The diameter of the sprayed false shaft neck was $70.1 \mathrm{~mm}$, and the length was $70 \mathrm{~mm}$. Gas-dynamic spraying of copper-based C-01-01 powder was performed in the modes corresponding to control samples 2 and 3 (table 1). Spraying was performed at half the length of the neck, the nozzle was located from the sample at a distance of $10 \ldots 11 \mathrm{~mm}$. In all spraying modes, a crack-free coating with a uniform thickness of $0.1 \mathrm{~mm}$ was obtained in one complete pass. As a result, after four passes, the coating had a relatively uniform thickness of $1 \mathrm{~mm}$ and required subsequent machining.

First sample (false shaft) it was pre - treated with corundum, and then with a rag soaked in white spirit. Turning was performed at the minimum spindle speed - no more than 100 rpm with a pass-through cutter with hard alloy plates and passed without peeling off the sprayed layer only at the early stages of the groove (cutting depth $0.05 \ldots 0.1 \mathrm{~mm}$ ). Further, during processing, there were delamination defects: cracks and chips. The maximum 
thickness of the sprayed layer before the occurrence of cracks during turning was $0.25 \ldots 0.3$ mm.

The second sample (false shaft) made of the same material and with the same geometric parameters as the first one was pre-processed by turning to obtain the 7 th...8th class of surface roughness ( $\mathrm{Ra} 1.26 \ldots 0.63$ and $0.63 \ldots 0.32$, respectively). Further, the surface was etched in two stages. At the first stage, the surface was freed from fats using the Detailan A-10 solution heated to 50 degrees Celsius. At the second stage, activation was carried out with a solution of hydrochloric acid. Degreasing was carried out using a jet-pouring method with copious rinsing with water. Chemical activation was carried out with a solution of hydrochloric acid with a concentration of $50 \mathrm{~g} / 1$ for $10-15$ seconds, followed by heavy washing with water.

Significant roughness of the pre-treated surface and etching allowed further turning of the sprayed false shaft without signs of cracks and peeling. So, a higher adhesion strength of the coating to the base metal was achieved. At the same time, the turning of the sprayed sample could be carried out until the coating was completely ground off without showing defects. Even with a deliberate increase in the depth of cut (almost to the base metal), delamination at the boundary of the transition from the sprayed layer to the base metal was not observed (Fig. 3).

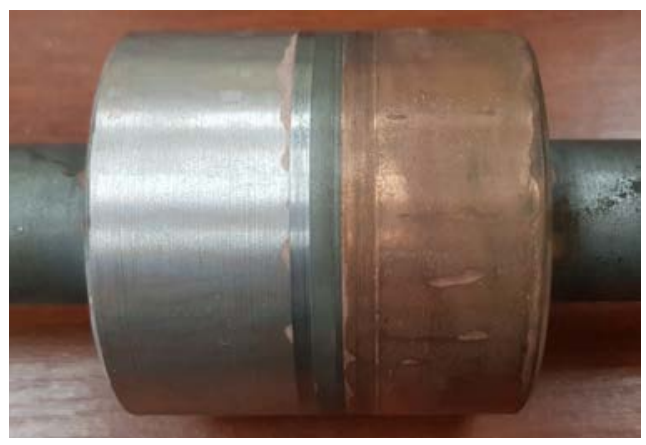

Fig. 3. Sample with pretreatment of the surface by rough turning and etching, gas-dynamic spraying with C-01-01 powder and the absence of delamination defects during subsequent turning.

So, it is recommended to build up shafts made of steel 20 with a surface micro-hardness in the range from 80 to 120 Vickers units by gas-dynamic spraying of a powder based on zinc or copper and zinc with heating of the air mixture in the range of $80 \ldots 150$ degrees Celsius and the powder flow range from 0.002 to $0.003 \mathrm{~kg} / \mathrm{s}$. When obtaining layers of small thickness $(0.1 \ldots 0.2 \mathrm{~mm})$ after gas-dynamic spraying of shafts made of steel 20 , it is recommended to perform the following pre-treatment to activate the surface of the base metal: turning to obtain the 7 th...8th purity quality, chemical etching with a Detailan solution A-10 and treatment with hydrochloric acid solution, followed by washing with water.

\section{References}

1. A.I. Ponomarev, V.M. Alakin, Development of technological recommendations for turbine component growing by small thickness layers, using gas-dynamic spraying method, Repair, restoration, modernization, v. 10, pp. 35-40 (2019)

2. A.P. Alhimov, S.V. Klinkov, V.F. Kosarev, V.M. Fomin, Cold gas-dynamic spraying. Theory and practice (Moscow: FIZMATLIT, 2009)

3. A.A. Spiridonov, Planning an experiment in the study of technological processes (Moscow: Mashinostroenie, 1981) 